\title{
The Prototype Of The Flood Disaster Early Detection System and Its Security
}

\author{
Wahyu Susilo $^{1}$, Edi Mulyana ${ }^{2}$, Lia Kamelia ${ }^{3}$ \\ \{whysusilo11@gmail.com¹, edim@uinsgd.ac.id²lia.kamelia@uinsgd.ac.id ${ }^{3}$ \} \\ Electrical Engineering Department, UIN Sunan Gunung Djati Bandung ${ }^{1,2,3}$
}

\begin{abstract}
Warning early detection of flood hazards and safety systems are needed to minimize losses of property and people. This study aims to design the building of an early flood detection system in a dam based on the water level in the dam and be integrated with its security system so that no one steals the system installed in the dam area. In this study two sensors are used, namely ultrasonic sensors to detect water levels and passive infrared (PIR) sensors as a safety detection system using Arduino Uno microcontroller. Measurement of water level based on the status of "standby (Siaga)" at Katulampa dam on a scale of 1:10. The test results at a water level of $6-23 \mathrm{~cm}$ have an average difference of $0.992 \%$ compared with water level information displayed via the LCD. The standby status sent via SMS to the user phone. PIR sensor test results on the maximum distance at $2.5 \mathrm{~m}$. If the status in the system is "Siaga", the system will call the registered user by phones. Based on the test results, the flood detection system and its security system were successfully implemented according to the initial scenario.
\end{abstract}

Keywords: Flood detection, PIR, Safety system, Ultrasonic.

\section{Introduction}

Flood disaster is one form of natural phenomenon that occurs due to high rainfall intensity so that there is excess water that is not accommodated by the drainage of an area. Flooding can be in the form of inundation on land that is usually dry, such as agricultural land, settlements, city centers. Flooding can also occur because the discharge/volume of water flowing in a river or drainage channel exceeds its drainage capacity. Water overflow is usually not a problem if it does not cause loss, death or injury, does not soak the settlement for a long time, does not cause other problems for daily life [1]. in 2018, in Indonesia 3,397 floods occurred, 3,874 people died and were missing, 21,171 people were injured and 563,135 people were affected \& displaced [2]. Every year the number of events increases dramatically. To reduce the effects of flood disasters, effective detection and mitigation systems must be implemented that starts from policies in the central government to implementation at the flood disaster site.

An early warning system was developed to predict natural disasters before this happened. these systems are usually operated on a large scale, with renewal cycles every hour and everyday, using variable complexity levels including pure statistical processes, geophysical modeling, and forecast-based impacts and economic evaluation [3]. Large-scale detection systems typically cover large areas with the use of high-resolution synthetic Aperture Radar (SAR) radar and image capture[4]. the use of Remote Sensing (RS) and Geographical Information System (GIS) technology using satellites can also be applied to monitor the 
direction of floods and predict the damage caused by floods. Flood monitoring using satellite data proved to be an effective method to get a fast and precise overview of flooded land [5]. Other Research integrates hydrological simulations of the LISFLOOD rainfall-runoff model for different scenarios with satellite-derived surface water extent through a data assimilation framework using the Ensemble Kalman Filter method [6].

The use of sensors in flood detection systems has been widely implemented to detect the occurrence of floods. In the [7] research, Ultrasonic sensor jsn-sn04t-2.0 is used. The sensor works by emitting a sound pulse (TRIG), then the width of the return pulse (ECHO) is measured and the distance (the water level) is calculated from the time differences between the Trig and Echo. The other researcher presents the way how to create a warning detection system using Arduino microcontroller combined with ultrasonic sensors, GSM (Global System for Mobile) \& GPRS (General Packet Radio Service) module where the concerned citizens can find out the information about the river water levels in real-time via website with their gadget, called Internet of Things (IoT) network [8].

For applications in the field, we need a system that can detect floods in the early stages. the use of ultrasonic sensors, flow sensors, and rain sensors is the examples of the sensor-based application system that is low cost, portable and accurate [9]. Other types of sensors used for flood detection are the integration of triaxial sensors, water level sensors and tilt sensors. The research of Yeon et al. proposed sensor devices to detect the river flooding in areas with a high risk of flooding. [10].

The application of sensors as a module of measuring environmental conditions is the initial use for the data collection process. The data obtained will be processed by the processor as the input and decision-making parameters for the decision-support system at the top layer.

One of the problems in a disaster detection system is a system security system. Many disaster detection devices such as floods, fires, and tsunamis are stolen. The loss of this tool will result in a huge loss, both from the number of victims or lost/damaged property. So that the existence of a flood detection system that is equipped with a safety system is important. flood detection and safety systems are a package that can not be separated

In [11] work, a smart early warning system was developed to reduce the number of lifethreating fires and robbery. Pyroelectric Infrared sensor used as the motion sensor to detect the intruder presence. Home security systems that use PIR sensors can also be combined with a webcam camera that will be active if the sensors detected the human presence[11]. Integration can be done with a face detection system that will activate the alarm system when detected human movements and intruder faces [12].

\section{Research Methodology}

The devices for the system involve Arduino Uno, Ultrasonic sensors to measure water levels in dams, PIR sensors as the human motion sensors to prevent damage/theft from intruders, and GSM SIM900a Module as SMS sender for the information to the user. Arduino Uno Microcontroller functions as a control for all modules both for output and input to the system and LCD 16X2, used to display flood information. The block diagram for the system showed in Fig.1. The ultrasonic sensor circuit detects the distance of the water level and works continuously. The sensor works by sending a frequency signal through the Transceiver (TX) until it hits the surface of the water and the signal will then be reflected back and will be received by the Receiver (RX). The PIR sensor circuit is used to detect obstacles from humans based on 
body temperature. The working principle of the PIR sensor is that it will be "HIGH" if the sensor detects movement from humans while the sensor will be "LOW" when there is no detection of human presence. The system design which is a combination of various planned materials is presented in Fig. 2.

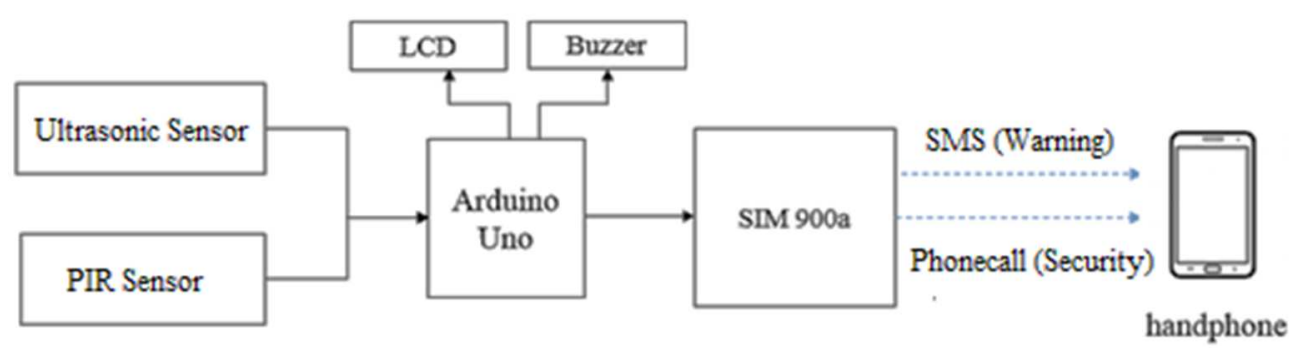

Figure 1. Diagram Block of the system

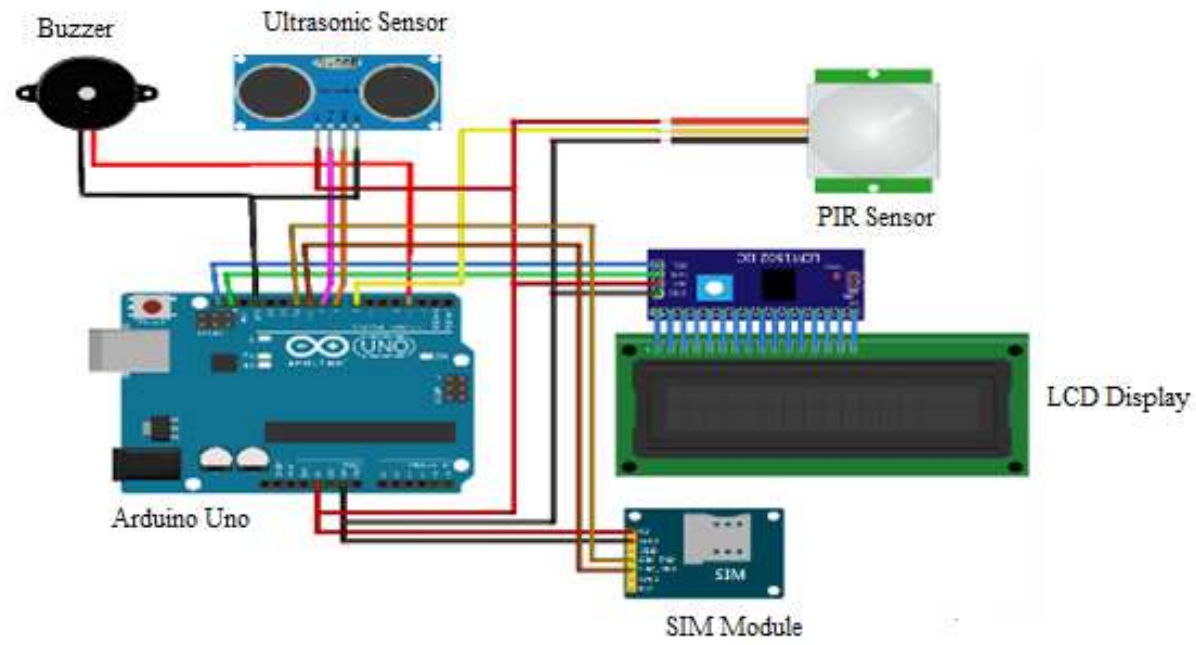

Figure 2. System Design

Determination of water level status is based on the Katulampa dam standard in Bogor. This standard will be simplified for making prototypes and will be used as initial settings which are then inputted into the program code. The Katulampa Dam Standard displayed in Table 1.

Table 1. Katulampa Dam Status Level

Alert Level Water high in the Dam $(\mathrm{cm})$




\begin{tabular}{ll} 
Level 1: Disaster (Bencana) & $>200$ \\
Level 2: Critical (Kritis) & $150-199$ \\
Level 3: Alert (Waspada) & $80-149$ \\
Level 4: Safe (Aman) & $<79$ \\
\hline
\end{tabular}

A warning process by the system is based on the level in table 1 . The system will send a text message to the telephone number that was previously registered based on the water level status. The text messages will contain the status of the dam at the time, so the notification system will be real-time. text messages will contain the status of the dam that is happening at the time, so the notification system will be real-time. Text messages will only be sent when the dam status is alert, critical and disaster. The system will make phone calls if there is detection of human movement around the system. This movement is considered as interference from strangers who will impair or steal the system.

\section{System Implementation}

The overall implementation is shown in Figure 1. The system created is a prototype of a system that can be built on a dam. In the implementation of dam size, the system must be made in several units, so that the measurement of water level in the dam can be calculated more accurately.

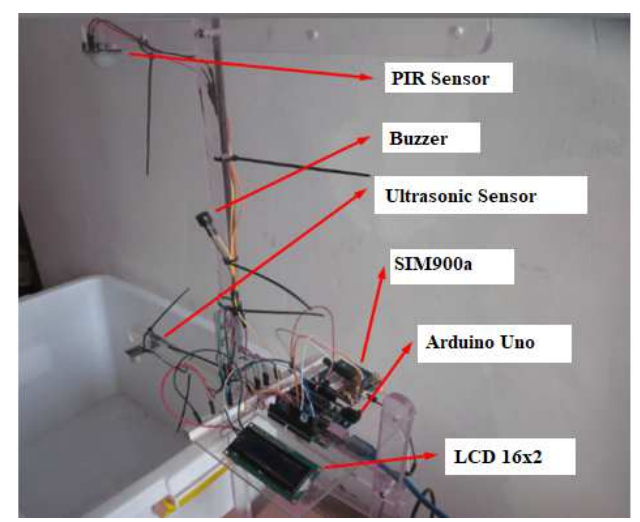

Figure 3. System implementation

The pin connections used for the implementation of the whole circuit are shown in Table 2. To simplify system implementation, the $5 \mathrm{v}$ pin as a voltage source and GND as the ground on Arduino are connected to the project board for efficient use of pins. The voltage source on the sim 900 uses the 2-Ampere charger. The PIR sensor output connected to Pin 2 on Arduino Uno. In the ultrasonic sensor, the trigger as the sender of the signal and echo to capture the reflected signal is connected to pins 8 and 9 to measure the water level. The output on the buzzer connected to pin 7 on Arduino Uno. SIM900a TX and RX modules are connected to pins 10 and 11 on Arduino using jumper cables.

\section{Results and Discussion}


The Tests Phase are carried out on each block to determine the performance of the device designed, testing includes:

1. Testing the connectivity of the HC-SR04 Ultrasonic Sensor Circuit with Arduino Uno

2. Testing connectivity on Passive-Infrared Sensors and Arduino Uno

3. Testing connectivity between LCD $16 \times 2$ with Arduino Uno

4. Testing SIM900a and Arduino Uno connections

5. Overall Testing

Table 2. Pin connections

\begin{tabular}{lll}
\hline \multicolumn{1}{c}{ Sensor/Modul Pin } & \multicolumn{1}{c}{ Pin Controller } & \multicolumn{1}{c}{ Function } \\
\hline Vcc, Ultrasonic & 5V, Arduino & Tegangan Ultrasonic \\
GND, Ultrasonic & GND, Arduino & Ground Ultrasonic \\
Trig, Ultrasonic & Pin 8, Arduino & Input Ultrasonic \\
Echo, Ultrasonic & Pin 9, Arduino & Input Ultrasonic \\
Vcc, PIR & 5V, Arduino & PIR Voltage \\
GND, PIR & GND, Arduino & Ground Ultrasonic \\
Output, PIR & Pin 2, Arduino & Keluaran PIR \\
Vcc, SIM900a & 5V, Charger 2A & tegangan SIM900a \\
GND, SIM900a & GND, Charger 2A & Ground SIM900a \\
TX, SIM900a & Pin 10, Arduino & Input TX \\
RX, SIM900a & Pin 11, Arduino & Input RX \\
GND, LCD & GND, Arduino & Ground LCD \\
VCC, LCD & 5V, Arduino & LCD voltage \\
SDA, LCD & SDA, Arduino & input LCD \\
SCL, LCD & SCL, Arduino & Input LCD \\
\hline
\end{tabular}

The first stage of testing is measuring the maximum distance that can be reached by the sensor. The pin used in ultrasonic sensor testing uses 3 pins, ie. pin 1 to $\mathrm{Vcc} 5 \mathrm{v}$, pin 2 to GND and pin 3 to pin 4 on Arduino Uno.

On normal condition, Arduino Uno has an LED indicator light that lights up orange which indicates that it is in the "HIGH" condition and the power indicator light will turn green when connected to a laptop via USB. When the Arduino Uno circuit and the sensor are connected, the sensor receives the voltage from the Arduino Uno on pin $5 \mathrm{~V}$ using the jumper cable and ground to the GND pin on the Arduino.

When Arduino Uno is started, the ultrasonic sensor sends a signal via pin 2 to the trigger on the sensor with a delay of $100 \mathrm{~ms}$. After the signal emitted from the trigger hits the object the signal is reflected and captured by ECHO and the signal is sent via pin 3 so that it can turn on the RX indicator lights on the Arduino Uno with a delay of $100 \mathrm{~ms}$ so that the lights will blink. The test results show the ultrasonic sensor is able to reach heights up to $402 \mathrm{~cm}$ displayed through a serial monitor.

PIR sensor testing is performed to detect the presence of strangers. The PIR circuit has 3 pins: the red wire is connected to Vec $5 \mathrm{v}$ on Arduino to get voltage, the black wire is connected to GND on Arduino as ground, and the gray wire is connected to pin 2 as input from the PIR sensor. When the circuit is run, in the initial condition the LED has a "LOW" status. In the LOW condition, the sensor will be reactive when there is detection of human motion. When the PIR sensor detects human movement, the sensor will send a signal through pin 2 so that the LED 
that was previously LOW status becomes HIGH or value 1. PIR sensors are capable of detecting objects up to 2.5 meters and sensors are sensitive to human presence.

Testing the LCD connection using 4 pins, red cable connected to $5 \mathrm{v}$ in Arduino for supply voltage to LCD 16x2, black cable to GND on Arduino, white cable connected to SDA / serial data pin on Arduino and blue cable to SCL / serial clock pin. The result of the testing of LCD displayed at Fig.2. The code used on the LCD is :
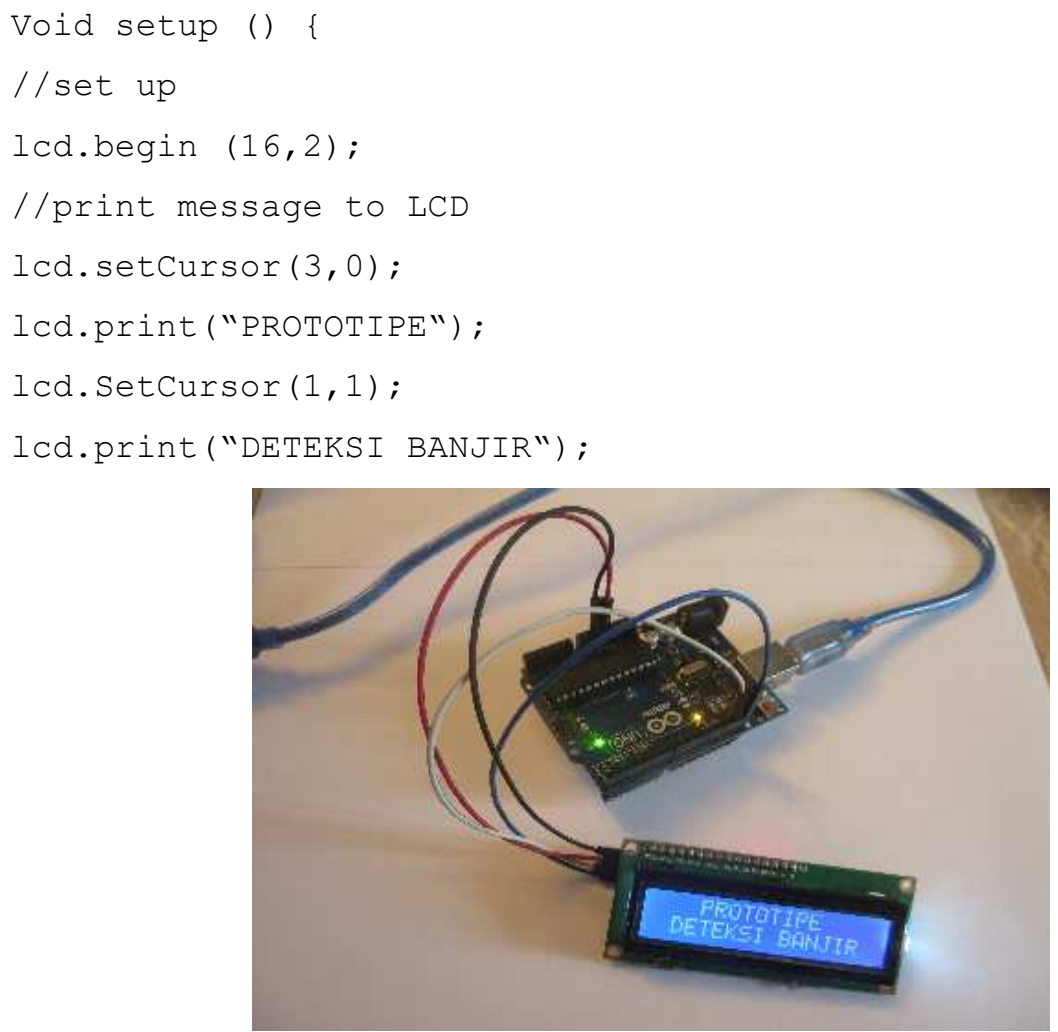

Figure 4. LCD testing

SIM900a GSM module is used to send information via SMS and telephone to the destination number specified in the previous program. In the circuit testing, 4 pins are needed, i.e. the red cable connected to the Arduino 5v pin, the black cable to the GND pin, the orange cable to pin 7 is used as the RX line that receives messages from mobile phones to the GSM sim 900a module and pins 8 is used as the TX line to send information from Arduino to SIM900a.

In experiments with water levels less than $8 \mathrm{~cm}$, no SMS was sent because the alarm was not set for "safe" conditions. After the experiments, the water level is more than $9 \mathrm{~cm}$ and less than $15 \mathrm{~cm}$ SMS messages have been sent successfully with the information content "alert". Experiments for water levels of more than $16 \mathrm{~cm}$ and less than $19 \mathrm{~cm}$, successful SMS messages were sent with the contents of the "Beware" information. In experiments for water levels of more than $20 \mathrm{~cm}$, an SMS message was successfully sent in a "hazard" condition. Sound alert 
from the buzzer is active for 5 seconds to give a warning to local residents that flooding might occur.After ultrasonic sensor measurements, the average difference of $0.992 \%$ is obtained. The complete results are presented in Table 2.

PIR sensor safety system testing was carried out 12 times with the scenario of a human presence and no human movement. When a human presence is detected by a PIR sensor there will be a phone call to the destination number for 10 seconds that has been set through the program each time a motion is detected.

Table 3. Results of Testing Phase

\begin{tabular}{|c|c|c|c|c|}
\hline Status & Water Height (Cm) & $\begin{array}{l}\text { Display On LCD } \\
(\mathrm{cm})\end{array}$ & SMS & Difference( $(\%)$ \\
\hline \multirow{3}{*}{ Safe } & 6 & 6,1 & No & 1,67 \\
\hline & 7 & 7,16 & No & 2,29 \\
\hline & 8 & 8,11 & No & 1,37 \\
\hline \multirow{3}{*}{ Alert } & 9 & 9,14 & Yes & 1,56 \\
\hline & 12 & 12,02 & Yes & 0,17 \\
\hline & 15 & 15,11 & Yes & 0,73 \\
\hline \multirow{3}{*}{ Critical } & 16 & 16,14 & Yes & 0,88 \\
\hline & 17 & 17,12 & Yes & 0,71 \\
\hline & 19 & 19,09 & Yes & 0,47 \\
\hline \multirow{3}{*}{ Disaster } & 20 & 20,12 & Yes & 0,60 \\
\hline & 21 & 21,18 & Yes & 0,86 \\
\hline & 23 & 23,14 & Yes & 0,61 \\
\hline \multicolumn{3}{|c|}{ Difference averagae0 } & & 0,992 \\
\hline
\end{tabular}

\section{Conclusions}

1. The SMS information sent by SIM900a consistent with the received-message on the handphone, the SMS information received contains "alert" at the water level of $9-15 \mathrm{~cm}$, "Critical" at water level of 16-19 cm and "Disaster" for water- height more than $20 \mathrm{~cm}$.

2. The flood detection prototype is used on a scale of 1:10 from the Katulampa dam water level standard. The average difference obtained in the overall test between the sensor and manual measurement is $0.992 \%$. Thus it can be concluded that the HC SR04 Ultrasonic sensor is suitable as a water level detector for the flood detection prototype. 
3. The maximum range that can be detected by the PIR sensor is $2.5 \mathrm{~m}$ with the output of telephone calls to the specified number for 10 seconds. PIR sensor is used as a safety prototype for flood detection from theft/vandalism by strangers

\section{References}

[1] R. Arief, "Banjir: Fakta dan Dampaknya, Serta Pengaruh dari Perubahan Guna Lahan," J. Perenc. Wil. dan Kota, vol. 24, no. 3, pp. 241-249, 2013.

[2]"Data Informasi Bencana Indonesia (DIBI)," 2018. [Online]. Available: http://bnpb.cloud/dibi/laporan5. [Accessed: 09-Aug-2019].

[3] L. Alfieri et al., "A global network for operational flood risk reduction," Environ. Sci. Policy, vol. 84, no. December 2017, pp. 149-158, 2018.

[4] D. C. Mason, L. Giustarini, J. Garcia-Pintado, and H. L. Cloke, "Detection of flooded urban areas in high-resolution Synthetic Aperture Radar images using double scattering," Int. J. Appl. Earth Obs. Geoinf., vol. 28, no. 1, pp. 150-159, 2014.

[5] M. Haq, M. Akhtar, S. Muhammad, S. Paras, and J. Rahmatullah, "Techniques of Remote Sensing and GIS for flood monitoring and damage assessment: A case study of Sindh province, Pakistan," Egypt. J. Remote Sens. Sp. Sci., vol. 15, no. 2, pp. 135-141, 2012.

[6] B. Revilla-Romero, N. Wanders, P. Burek, P. Salamon, and A. de Roo, "Integrating remotely sensed surface water extent into continental-scale hydrology," J. Hydrol., vol. 543, pp. 659-670, 2016.

[7] E. Leon, C. Alberoni, M. Wister, and J. Hernández-Nolasco, "Flood Early Warning System by Twitter Using LoRa," Proceedings, vol. 2, no. 19, p. 1213, 2018.

[8] J. W. Simatupang and F. Naufal, "Flood Early Warning Detection System Prototype Based on IoT Network," Internetworking Indones. J., vol. 11, no. 1, pp. 17-22, 2019.

[9] E. Basha and D. Rus, "Design of early warning flood detection systems for developing countries," 2007 Int. Conf. Inf. Commun. Technol. Dev. ICTD 2007, no. January 2008, 2007.

[10] S. Yeon, J. Kang, and I. Lee, “A study on real-time flood monitoring system based on sensors using flood damage insurance map," Int. Arch. Photogramm. Remote Sens. Spat. Inf. Sci. - ISPRS Arch., vol. 42, no. 3W4, pp. 569-571, 2018.

[11] K. Kumar, N. Sen, S. Azid, and U. Mehta, "A Fuzzy Decision in Smart Fire and Home Security System," Procedia Comput. Sci., vol. 105, no. December 2016, pp. 93-98, 2017.

[12] N. Surantha and W. R. Wicaksono, "Design of Smart Home Security System using Object Recognition and PIR Sensor,” Procedia Comput. Sci., vol. 135, pp. 465-472, 2018. 